\title{
Reseña del libro La Ética Protestante y el Espíritu del Capitalismo
}

\author{
Review of the book The Protestant Ethic and Spirit of Capitalism \\ Revisão do livro Ética Protestante e o Espírito do Capitalismo
}

\author{
Manuel Kamichi \\ Universidad Nacional Mayor de San Marcos \\ Manuel.Kamichi@unmsm.edu.pe \\ Código Orcid: https://orcid.org/0000-0002-3222-3319
}

La Ética Protestante y el Espíritu del Capitalismo

Autor: Max Weber

Editorial: Alianza Editorial

ISBN: 978-84206-69-46-5

Edición: 2012 (2da. Edición)

Max Weber (1864-1920) fue un sociólogo y economista alemán, considerado como el fundador de la sociología moderna junto a Karl Marx y Emile Durkheim. Entre sus investigaciones se encuentra la búsqueda de la relación entre la cultura y la economía, que se puede observar en su obra $\mathrm{La}$

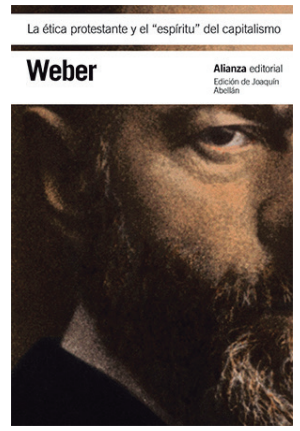
Ética Protestante y el Espíritu del Capitalismo.

La presente reseña tiene como objetivo demostrar la vigencia del argumento de Weber en la actualidad. Para ello, se han analizado los aspectos de la ética del protestantismo ascético que el autor indica como las causantes del desarrollo del capitalismo, y se demuestra cómo es que este sistema económico sigue vigente debido a la continuidad de la ética en las personas. En segundo lugar, se ha respondido a las críticas de los economistas Jeffrey Sachs (2006) y Ha-Joon Chang (2007) a la tesis de Weber cuando muestran cómo el capitalismo se ha desarrollado más rápido en países católicos que protestantes.

Ante esto, lo que se demuestra en el presente texto es que el argumento de Weber sigue vigente en cuanto nos enfocamos en la esencia del mismo, que es la necesidad de una ética tan fuerte que haga a las personas actuar acorde al sistema económico que se quiere desarrollar. Si las personas no actúan según la ética necesaria para el desarrollo de un sistema económico, ésta no se va a poder desplegar.

En el caso de la investigación de Weber en su obra, lo que descubrió es que fue la religión del protestantismo ascético la que pudo infundir la ética para el desarrollo 
del sistema económico capitalista; y por más que a lo largo de la historia puede que la causante de la ética haya variado, ya no la religión sino otras, la tesis esencial del autor, que es que para el desarrollo de un sistema económico es necesario que las personas actúen en base a una ética acorde para su progreso, sigue vigente.

En el libro La Ética Protestante y el Espíritu del Capitalismo, Weber expone la tesis que existe la influencia de ciertos ideales religiosos en la formación de una mentalidad económica. Señala que la ética necesaria para el desarrollo del sistema capitalista concuerda con la mentalidad de los ideales religiosos del protestantismo ascético. Estas son: la vida racionalizada, impulso al trabajo y fomento del ahorro; mientras que las demás religiones tienen dificultades para desarrollar el capitalismo porque su ética no coincide con las necesarias para el progreso de este sistema económico.

Se ha tratado de desprestigiar la obra de Weber al considerar que la tesis se equivoca al tratar de indicar la existencia de culturas que predisponen al desarrollo económico más que otras; como por ejemplo, el del protestantismo en el capitalismo (Chang, 2007), o al señalar que la tesis del libro falla al explicar el desarrollo económico en las regiones según los valores religiosos de los países (Sachs, 2006). Lo real es que se ha descontextualizado la obra de Weber. Cuando uno realiza una investigación social se debe ubicar a los sujetos en los contextos donde se encuentran (Osorio, 2001).

Weber encontró que en el siglo XVI y XVII solo la fe religiosa podía romper con el tradicionalismo económico, donde las personas solo deseaban ganar los suficiente para vivir. En este contexto, fue la religión protestante la que desarrolló el espíritu capitalista, al poder implantarles a sus seguidores el deber de enriquecerse y organizar su vida en torno a la acumulación de dinero.

La vigencia de la obra de Weber es la comprobación que hace al demostrar que para el desarrollo de un sistema económico debe existir una correlación entre las actitudes de los sujetos con los requerimientos necesario para el progreso de ese sistema, independientemente si esas actitudes provienen de la religión o no.

Una de sus comprobaciones es que para el desarrollo del capitalismo se requiere la entrega total de los sujetos para ganar dinero, el espíritu de la acumulación. Immanuel Wallerstein señaló que uno se encuentra en un modelo capitalista cuando hay un proceso incesante de acumulación de capital con el objetivo de acumular más capital (Wallerstein, 2005), esto claramente está motivado por la avaricia, como lo señaló Keynes al indicar que la avaricia es necesaria para el desarrollo del capitalismo, al afirmar que esta era uno de los factores -junto a la usura y la cautela- que nos iba a salvar de la necesidad económica (Keynes J. , 1963).

Weber también señala en su obra que existe un cálculo racional de por medio. Cuando uno analiza el ciclo del capitalismo: dinero - capital - más dinero ( $C$ - $M$ - $\left.C^{\prime}\right)$, se encuentra que la motivación para seguir invirtiendo por parte de los capitalistas es si es que las ganancias superan los costos de producción; por lo cual, es un medio eficiente para acumular riqueza (Esteve, 2017 ). Esto es algo que comprueba Keynes al descubrir que el incentivo para invertir es resultado de la relación que existe entre las tasas de interés con la eficiencia marginal del capital; que es la relación de las expectativas del uso del bien de capital con su coste de reposición (Keynes, 1986).

Es decir, si las ganancias futuras superan los costos del capital y es en una cantidad considerada óptima para el capitalista, se ejecuta la inversión. Esto coincide con lo que escribió Weber en su obra al señalar que para el desarrollo del capitalismo debe existir un cálculo racional y planificada para el éxito económico, que es el satisfacer el espíritu de la acumulación. Si no hay un espíritu de la acumulación y un cálculo racional para satisfacerlo, los inversionistas no estarían motivados a invertir, y si no hay inversión, no hay capitalismo. 
En la actualidad, el sistema económico capitalista continúa porque hay personas que actúan en base a esa misma ética, la racionalización para la búsqueda del enriquecimiento, tal vez ya no motivada por la religión, como concluyó Weber en su investigación, pero independientemente de lo que cause que las personas adopten esa ética, el hecho que se mantenga, hace que este sistema económico también lo haga porque esas personas actúan según los requerimientos del sistema para su desarrollo.

Weber también señala el ascetismo como una de las características en el desarrollo del capitalismo, puesto que permite el enriquecimiento empresarial. Esto es algo que coincide Erich Fromm al indicar que el modo de producción capitalista aumentó el espíritu ascético (Fromm, 2011).

Las grandes compañías tratan de reducir los costos de producción al mínimo (Klein, 2001); esto concuerda con la idea de que el capital en la función de la producción [O $=\mathrm{f}(\mathrm{L}, \mathrm{C})$ ] debe medirse de acuerdo con sus costos pasados, y no con la capacidad de ganancia futura (Robinson, 1953-1954); por lo que, a menores costos en la producción, mayores tasas de producción, y por ende, mayores tasas de ganancias. Considerando que esta última depende del salario, de la composición orgánica del capital y de la productividad del trabajo (Esteve, 2017), se concluye que a menores salarios, mayores ganancias para el inversor. Esto se puede observar en la fórmula: $g^{\prime}=p /(v+c)$, en donde hay una relación directa entre tasa de ganancia $\left(\mathrm{g}^{\prime}\right)$ con la plusvalía (p); a mayor plusvalía, entonces, mayor tasa de ganancia.

Esto ha traído consigo que una parte del desempleo en los países industrializados se deba a la deslocalización de la producción, como en los Estados Unidos, que esto ha generado un aproximado de un tercio de las pérdidas del empleo en los últimos años (Harvey, 2012).

Esta realidad extendida a nivel mundial coincide con dos características de la ética protestante que indica Weber, el impulso al trabajo y el ascetismo. Se trata de tener trabajadores eficientes; es decir, que tengan altos niveles de productividad y al menor costo posible. Esta característica lo pregonaba el ascetismo protestante, puesto que mostraba al trabajo como el único medio para llegar al estado de gracia y concebir el enriquecimiento del empresario como una profesión. Mientras las personas continúen con esta ética, también continuará el sistema capitalista, sin importar si ésta es adoptada por razones religiosas.

Otro punto clave que descubre Weber en su obra, que es característico de los protestantes y que fue favorable para el desarrollo del capitalismo, es el ahorro, puesto que esto beneficia a la inversión por ser opuesta al consumo. Esto se puede comprobar con la propuesta del economista, y uno de los grandes defensores del capitalismo, Milton Friedman, quien planteó gravar los gastos para estimular el ahorro; y con ello, reducir el consumo (Béjar, 2011). La lógica es que para invertir se debe tener dinero, y para ello, se debe ahorrar; y para ahorrar se debe disminuir el consumo.

Weber descubre en su obra que los católicos tienen poca participación en el capitalismo debido a que prefieren los institutos humanistas. Sobre esto, es interesante señalar que los valores católicos son opuestos al capitalismo, por lo que los católicos no deberían desarrollar el capitalismo (Urbina, 2019). El papa Pio XI condenó el capitalismo, el papa Juan XXIII apoyó la sindicalización y el salario justo, el papa Pablo VI criticó la codicia por obtener ganancia, el papa Benedicto XVI señaló la necesidad de transformar la estructura de la sociedad para lograr justicia social (Gallagher, 2014) y el papa León XIII también criticó al capitalismo (Béjar, 2011).

Entonces, la cuestión es saber por qué en la segunda mitad del siglo XX, los países católicos crecieron con rapidez en un sistema capitalista como las católicas Francia, Austria y Alemania meridional (Chang, 2007), donde además la Italia y la Irlanda católicas superaron a la Gran Bretaña protestante en renta per cápita (Sachs, 2006). La 
respuesta la da el propio Weber en el libro cuando indica que la disposición psíquica se debe manifestar en el comportamiento. Esto quiere decir que las personas pueden decir que son católicas en el discurso, pero no llevar esa religiosidad a la práctica. Por eso es que puede haber países con poblaciones que en el discursos señalan ser católicas, pero en la práctica se comportan a favor del capitalismo, siendo totalmente contrarias.

Es falso decir que la religión es el impulsor de los comportamientos que desarrollan los sistemas económicos, lo que muestra Weber en su obra es que en el contexto que él estudio sí lo fue, pero en otros contextos la adopción de valores que derivan en comportamientos correlacionados al desarrollo de ciertos sistemas económicos son múltiples. Por ejemplo, Ernest Bader fue dueño de la empresa Scott Bader Co. Ltd., pero lo entregó a su comunidad debido a su filosofía en contra del capitalismo y a favor de la propiedad en común (Schumacher, 1978), la economía andina se basa en la solidaridad y la cooperación debido a su tradición organizativa (Marañón-Pimentel, 2012), la adopción de un comportamiento disciplinado en Japón, Alemania y Corea del Sur se debió a la implantación de los nuevos modos de producción (Chang, 2007) y la creación del estado de bienestar en Suecia fue gracias a la organización sindical que derivó en el tratado de 1938 en Saltsjöbaden (Béjar, 2011).

Por lo que la vigencia de la obra de Weber está en la comprobación que hizo de que para que se desarrolle un sistema económico es necesario una ética que haga que las personas se comporten según los requerimientos de ese sistema económico, en donde la formación de esa ética varía según los contextos.

\section{Bibliografía}

Béjar, H. (2011). Justicia social, política social. Lima, Perú: Achebé ediciones.

Chang, H.-J. (2007). ¿Qué fue del buen samaritano? Barcelona, España: Intermón Oxfam Editorial.

Esteve, F. (23 de Marzo de 2017 ). Economía Marxista (SEMPKC): Las Crisis del Capitalismo desde una Perspectiva Marxista . Disponible en: HYPERLINK "https://www. youtube.com/watch?v=me5efjHw90M\&t=4275s" https://www.youtube.com/ watch? $v=$ me5efjHw90M\&t=4275s [Fecha de consulta: $11 /$ diciembre/2019].

Fromm, E. (2011). El miedo a la libertad. Buenos Aires, Argentina: Paidós.

Gallagher, V. A. (2014). El verdadero costo de los precios bajos. Buenos Aires, Argentina: Grupo editorial Lumen.

Harvey, D. (2012). El enigma del capital y la crisis del capitalismo. Madrid: Akal

Keynes, J. (1963). Economic Possibilities for our Grandchildren. En J. Keynes, Essays in Persuasion (págs. 358-373). New York, Estados Unidos: W.W.Norton \& Company.

Keynes, J. M. (1986). Teoría general de la ocupación, interés y el dinero. México D. F., México: Fondo de Cultura Económica.

Klein, N. (2001). No logo : el poder de las marcas. Bacelona, España: Paidós.

Marañón-Pimentel, B. (2012). La colonialidad del poder y la economía solidaria. Apuntes para la reflexión teórico-metodológica del Grupo de Trabajo Economía Solidaria. En B. Marañón-Pimentel (Coord.), Solidaridad económica y potencialidades de transformación de América Latina. Una perspectiva descolonial (págs. 21-58). Buenos Aires, Argentina: CLACSO.

Robinson, J. (1953-1954). The Production Function and the Theory of Capital. Review of Economic Studies, XXI(2), 81.

Osorio, J. (2001). Fundamentos del análisis social. La realidad social y su conocimiento. México D.F., México: Universidad Autónoma Metropolitana, Unidad Xochimilco y Fondo de Cultura Económica. 
Sachs, J. (2006). El fin de la pobreza. Bogota, Colombia: Random House Mondadori.

Schumacher, E. F. (1978). Lo pequeño es hermoso. Madrid, España: Hermann Blume.

Urbina, D. A. (22 de Marzo de 2019). "No se puede servir a dos amos": Capitalismo y secularización. Disponible en: https://www.youtube.com/watch?v=2Qi0QEtB970 [Fecha de consulta: 11/diciembre/2019].

Wallerstein, I. (2005). Análisis de sistemas - mundo. Una introducción. México D.F., México: Siglo veintiuno editores. 
